\title{
ANALYSIS OF ALLOY INFLUENCE ON THE JOINT FORMATION IN COMPOUND FORGING OF GEARED STEEL-ALUMINIUM COMPONENTS
}

\author{
${ }^{1}$ Bernd-Arno BEHRENS, ${ }^{1}$ Kai BRUNOTTE, ${ }^{1}$ Philipp KUWERT \\ 1'Institut für Umformtechnik und Umformmaschinen (Forming Technology and Machines), Leibniz Universität \\ Hannover, Garbsen, Germany, EU, \\ kuwert@ifum.uni-hannover.de, brunotte@ifum.uni-hannover.de, behrens@ifum.uni-hannover.de
}

https://doi.org/10.37904/metal.2020.3487

\begin{abstract}
In order to reduce $\mathrm{CO}_{2}$ emissions, lightweight constructions and the use of steel-aluminium components have become increasingly important in current product development. When manufacturing such components, the dissimilar chemical and physical properties of these materials lead to major challenges in terms of metallurgical bond formation during joining. In particular, chemical compositions have a major impact on the joint properties and have therefore already been intensively investigated in welding technology. With regard to forming technology, the issue arises whether these findings can be transferred to simultaneous forming and joining for the manufacturing of steel-aluminium components by compound forging. In the scope of this study, aluminium workpieces were therefore alloyed with defined amounts of common welding additives such as zinc, nickel and silicon using powder metallurgy. Subsequently, these workpieces were forged together with steel and subjected to metallographic examination. The studies show that compound forging of the used alloy configurations is basically possible - however, bond formation varies significantly with different chemical composition. Alloying with zinc and silicon results in a reduced liquidus temperature and consequently in melting. In contrast, alloying with nickel leads to an extended joining zone and benefits the maximal mechanical load capacity.
\end{abstract}

Keywords: Powder metallurgy, compound forging, lightweight

\section{INTRODUCTION}

There are several material and process related limitations when monolithic components are used in applications, in which different regions of the components are subjected to different loads. In order to bear these loads efficiently while maintaining low weight, components can be tailored to their specific local requirements as for example as steel-aluminium components [1]. When joining steel and aluminium metallurgically, brittle intermetallic Fex-Aly phases may occur and can affect the bonding strength depending on the phase thickness [2]. The relationships that arise in this context have already been investigated extensively in the field of welding of steel-aluminium sheets. Song et al. joined steel and aluminium sheets by TIG welding-brazing with aluminium-silicon filler wires [3]. They pointed out that the addition of silicon prevents the formation of intermetallic phases (IMP) and minimises their thickness, due to the diffusion-inhibiting effect of silicon [4]. By adding nickel and zinc, other intermetallic phases such as $\mathrm{Al} x \mathrm{Zn} y, \mathrm{Fe}_{x} \mathrm{Zn}_{y}, \mathrm{Al}_{x} \mathrm{Ni}_{y}$ or $\mathrm{Fe}_{x} \mathrm{Ni}_{y}$, can be formed [5]. In comparison to classic FexAly phases, these mentioned phases have a higher ductility and a smaller negative effect on the bonding strength [6].

In order to save energy and resources in the manufacturing of steel-aluminium components, technologies combining forming and joining in one single operation can be used. One of these technologies is compound forging, where joining is achieved by creating a metallurgical and/or mechanical bond during forming. Figure 1 demonstrates an example of a corresponding process chain, being used in this study, Firstly, an aluminium 
core is inserted in a steel casing to obtain a hybrid workpiece. Then, the hybrid workpiece is heated inductively and finally formed in a closed die forging process to manufacture a hybrid part, such as a geared hybrid component.

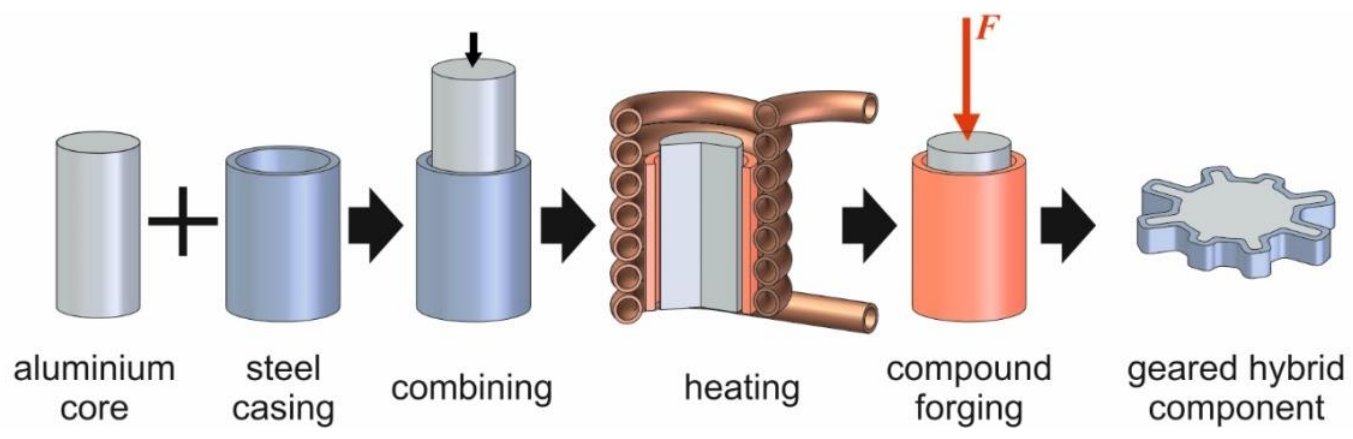

Figure 1 Overview of an exemplary process chain of compound forging

In order to influence the properties of the joining zone during compound forging, it is possible to apply the above-mentioned filler material (nickel, zinc or silicon) as a coating to the aluminium core or adding it as an alloying element. In compound forging, such coating systems are not sufficient. During forming, the high surface expansion of the materials results into a decreased coating thickness and can even end into a complete destruction of the coating layers. Both effects influence the joining process negatively. Alloying the aluminium core with the corresponding element leads to a diverging melting and heat conduction behaviour. Combined with the heat exchange to the steel, there is a high risk of melting during compound forging. Consequently, this results in poor bonding properties [7]. With regard to the influence of alloying elements on IMP formation, the question arises whether the above-mentioned findings on the welding of aluminium and steel can be transferred to compound forging. In this paper, this question is addressed utilising a compound forging process to manufacture a geared steel-aluminium component (Figure 1). The aim is to use nickel, zinc and silicon as alloying elements in order to influence the joining properties specifically and to identify process limits. Based on these findings, methods can be developed to manufacture steel-aluminium components with optimised bonding properties.

\section{MATERIALS AND METHODS}

In order to accomplish this aim, aluminium cylinders were first manufactured in different alloy configurations by means of powder metallurgy. These were assembled with a soft annealed steel case (AISI 1060) as shown in Figure 1, then heated and compound forged in order to manufacture a geared steel-aluminium component. By adjusting different tooth lengths, as illustrated in Figure 1, the surface expansion was varied within a range of $50 \%, 55 \%, 65 \%$ and $73 \%$. After forming, the parts were separated and metallographically examined, focussing on the joining zone.

For manufacturing different aluminium alloys, a ready-to-press powder mixture (Alumix 123, company Kymera International, formerly Ecka Granules) was used and combined with each of the following elemental powders with $5 \mathrm{wt} . \%$ and $10 \mathrm{wt} . \%$ : zinc, silicon and nickel. This resulted in seven different types of aluminium cores. In the following, these aluminium cores are assigned to the separately added alloying element in the corresponding weight grade, namely Alumix 123, $5 \mathrm{Zn}, 10 \mathrm{Zn}, 5 \mathrm{Si}, 10 \mathrm{Si}, 5 \mathrm{Ni}$ and $10 \mathrm{Ni}$ (Table 1). The green bodies were manufactured by double-sided pressing with an average compaction pressure of $600 \mathrm{MPa}$ on a multi-axis powder press from SMS Meer and then heat treated in a sintering process. For this, all green bodies were heated under vacuum ( $p<1 \mathrm{mbar}$ ) to $400^{\circ} \mathrm{C}$ for over $15 \mathrm{~min}$ and subsequently sintered for $30 \mathrm{~min}$ at $570{ }^{\circ} \mathrm{C}$ and cooled to room temperature. Table 1 contains the corresponding chemical composition of the alloyed aluminium cores and the specific solidus- and liquidus temperature, which was calculated based on the state of the recent literature. 
Table 1 Chemical composition and solidus and liquidus temperature of manufactured aluminium cores [8]

\begin{tabular}{|c|c|c|c|c|c|c|c|c|}
\hline & Al (wt.\%) & Cu (wt.\%) & Si (wt.\%) & Mg (wt.\%) & Zn (wt.\%) & Ni (wt.\%) & $\begin{array}{c}\text { Solidus } \\
\text { temper- } \\
\text { ature } \\
\left({ }^{\circ} \mathbf{C}\right)\end{array}$ & $\begin{array}{c}\text { Liquidus } \\
\text { temper- } \\
\text { ature } \\
\text { (' } \mathbf{C})\end{array}$ \\
\hline Alumix 123 & 94.40 & 4.50 & 0.60 & 0.50 & 0.00 & 0.00 & 558 & 648 \\
\hline $\mathbf{5 Z n}$ & 89.68 & 4.28 & 0.57 & 0.48 & 5.00 & 0.00 & 530 & 635 \\
\hline $\mathbf{1 0 Z n}$ & 84.96 & 4.05 & 0.54 & 0.45 & 10.00 & 0.00 & 530 & 630 \\
\hline $\mathbf{5 S i}$ & 89.68 & 4.28 & 5.57 & 0.48 & 0.00 & 0.00 & 520 & 608 \\
\hline $\mathbf{1 0 S i}$ & 84.96 & 4.05 & 10.54 & 0.45 & 0.00 & 0.00 & 520 & 580 \\
\hline $\mathbf{5 N i}$ & 89.68 & 4.28 & 0.57 & 0.48 & 0.00 & 5.00 & - & 630 \\
\hline $\mathbf{1 0 N i}$ & 84.96 & 4.05 & 0.54 & 0.45 & 0.00 & 10.00 & & - \\
\hline
\end{tabular}

An important criterion is to obtain an adequate forming result, specific heating strategies and an appropriate temperature gradient between steel and aluminium are needed, to adjust almost equal flow stresses [9]. This requires an inhomogeneous heating in which steel is heated to forming temperatures in a range between $900-1,200{ }^{\circ} \mathrm{C}$. The aluminium is heated to $250-350^{\circ} \mathrm{C}$ [10]. For this matter, induction heating experiments were carried out using a mid-frequency generator (Hüttinger TruHeat MF 3040) with a voltage output of $300 \mathrm{~V}$ and maximum power output of $40 \mathrm{~kW}$. The workpieces were combined, placed in the inductor and thermocouples were positioned in case and core of the aluminium workpieces and near the case of the steel workpiece to monitor temperature distribution. During three different power-time stages, the steel was firstly heated inductively with a $50 \%$ power-output for $10 \mathrm{~s}$ to forming temperature (Stage 1). In a time-range of $5 \mathrm{~s}$, the heat was transferred from the case to the aluminium core without any power-output to adjust the necessary inner forming temperature (Stage 2). Finally, the case was reheated inductively up to the origin forming temperature by a power-output of $50 \%$ for $8 \mathrm{~s}$ (Stage 3). By the application of this heating-profile, all combinations were heated to the desired temperature field (Table 2). Adjusting equal forming temperatures between the combinations was not possible due to the different thermal conductivities of the alloyed aluminium cores.

Table 2 Steel and aluminium temperatures for all combinations before compound forging

\begin{tabular}{|c|c|c|c|c|c|c|c|}
\hline & $\begin{array}{c}\text { Alumix } \\
\mathbf{1 2 3}\end{array}$ & $\mathbf{5 Z n}$ & 10Zn & 5Si & 10Si & 5Ni & 10Ni \\
\hline Steel temperature $\left({ }^{\circ} \mathbf{C}\right)$ & 779.6 & 835.3 & 725.9 & 793.8 & 798.4 & 794.1 & 748.4 \\
\hline Aluminium temperature $\left({ }^{\circ} \mathbf{C}\right)$ & 284.2 & 293.3 & 321.5 & 280.7 & 279.1 & 264.2 & 316.3 \\
\hline
\end{tabular}

After the heating tests, compound forging experiments were carried out using a fully automated forging cell with a screw press of $5 \mathrm{MN}$ nominal force. The forming tools were heated to a target temperature of $300{ }^{\circ} \mathrm{C}$ using heating cartridges and being lubricated with the dry lubricant CON TRAER G 300 . The combined steelaluminium workpieces were polished mechanically, cleaned in an ultrasonic bath, inserted in the inductor, heated, transferred to the forming tool within $5 \mathrm{~s}$ by a robot, compound forged and quenched. After compound forging, the hybrid components were cut by wire EDM (electro-discharge machining) according to Figure 2. Material distribution and joint formation were investigated by means of light microscopy.

\section{RESULTS AND DISCUSSION}

During the experiments, except from AISI1060-5Si and AISI-10Si, all material combinations were compound forged without internal blowholes and meltings in the aluminium core. Figure 2 shows the manufactured component and material distribution ( $\mathrm{St}=$ steel; $\mathrm{Al}=$ aluminium). The visual inspections of section 1-1 till 4-4 
revealed increasing local meltings in the contact zone for all material combinations. Furthermore, above level 2-2 internal cracking starts in the aluminium, and above level 3-3 also in the steel case. This is probably due to reduced formability within the corresponding temperature range of the steel material. Forming temperatures were not increased because further melting of the aluminium core was expected.
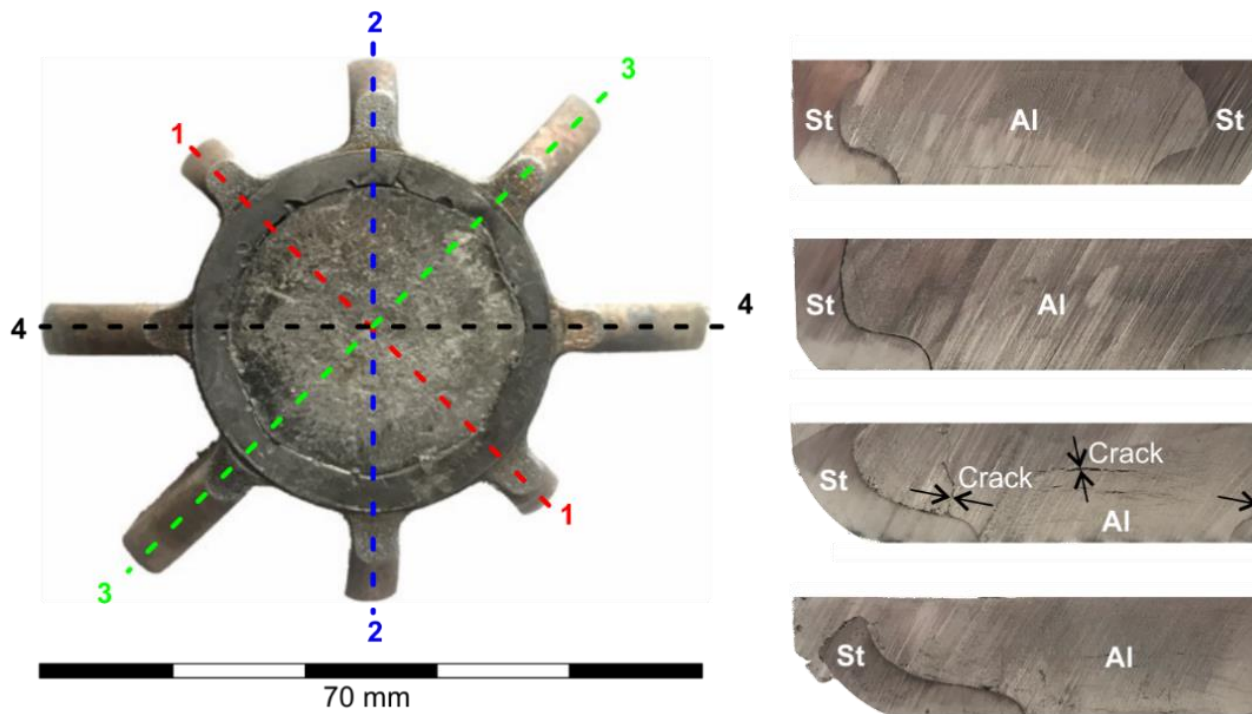

Section 1-1

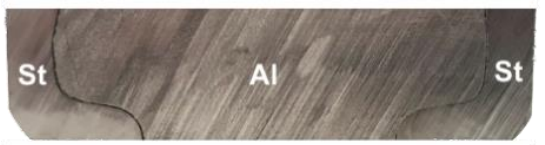

Section 2-2

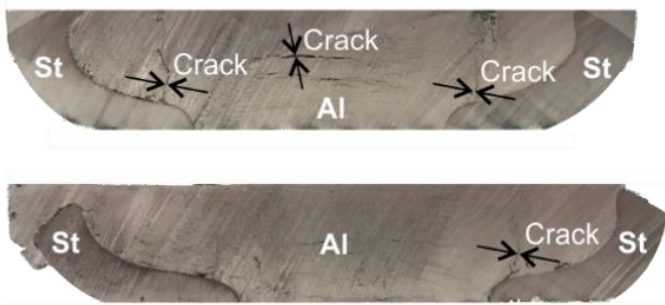

Section 3-3

Figure 2 Compound forged hybrid component (Combination: AISI 1060-5Si)

In metallographic investigations, a continuous air gap between steel and aluminium was detected in all tooth planes of the investigated material combinations (Figure 3). This might result from the higher coefficient of thermal expansion of the aluminium cores leading to high shrinkage cavities. When analysing the contact zone, it can be seen that the roughness of the materials represents the respective counterpart to each other (Figure 3). Thus, a contact between steel and aluminium seems to exist during the forming process and an adequate joining takes place. At the same time, deformation and heat exchange lead to an increase in the forming temperature of the aluminium core. During quenching, the shrinkage of the aluminium cores predominates and results in a destruction of the joining zones, so that aluminium breakouts adhere exclusively to the steel case. In the following, the joining line was analysed and marked graphically, as illustrated exemplarily in Figure 3 for AISI1060-Alumix 123, and the thickness measured in this range. For a better comparison, the maximal joining line thickness for all combinations is summarised in Table 3.

Table 3 Overview of the maximal joining line thickness resulting from compound forging

\begin{tabular}{|c|c|c|c|c|}
\hline & Section 1-1 & Section 2-2 & Section 3-3 & Section 4-4 \\
\hline $\begin{array}{c}\text { Joining line thickness } \\
\text { Alumix 123 }(\boldsymbol{\mu m})\end{array}$ & $0.8 \pm 0.1$ & $1.7 \pm 0.2$ & $2.2 \pm 0.1$ & - \\
\hline Joining line thickness 5Ni $(\boldsymbol{\mu m})$ & $2.0 \pm 0.7$ & $0.7 \pm 0.1$ & $0.80 \pm 0.3$ & - \\
\hline Joining line thickness 10Ni $(\boldsymbol{\mu m})$ & - & $1.40 \pm 0.3$ & $4.8 \pm 1.2$ & $5.1 \pm 0.6$ \\
\hline Joining line thickness 5Si $(\boldsymbol{\mu m})$ & $0.80 \pm 0.30$ & - & - & - \\
\hline Joining line thickness 10Si $(\boldsymbol{\mu m})$ & $1.1 \pm 0.4$ & - & - & - \\
\hline
\end{tabular}

By varying the surface expansion by $50 \%$ (section 1-1), $55 \%$ (section 2-2), $65 \%$ (section 3-3) and $73 \%$ (section 4-4), no clear growth in the thickness of the joining line can be recorded (Table 3). Similar to cold welding, presumably only a threshold value must be exceeded in order to establish a metallurgical joint [11]. In contrast, alloying influences material properties extensively and thus, joining behaviour. While the 
AISI 1060-Alumix 123 combination merely showed short, segmented joining lines, alloying with nickel led to a significant increase in the continuity of the joining lines and increased with higher nickel content. This is probably due to the increased diffusion tendency and has also been observed in the welding of steel-aluminium sheets with nickel coating [7]. Due to the increasing length of the joining line and the resulting increase of the joining area, an increase in maximum load capacity is expected. In contrast, alloying with zinc, compared to the reference combination AISI 1060-Alumix 123, leads to a destruction of the joining zones. By adding this element, the liquidus and solidus temperature were reduced considerably and at the same time the heat conduction coefficient increased, so that during induction heating, higher forming temperatures are achieved. Both effects favour fusion metallurgical joining, but no material compound can be identified in all tooth planes of the AISI 1060-5Zn and AISI 1060-10Zn combinations. A comparable joining behaviour also exists among copper-alloyed AIZn wrought alloys, which are comparable in their chemical composition to the aluminium cores $5 \mathrm{Zn}$ and $10 \mathrm{Zn}$. During the joining of copper-alloyed AIZn wrought alloys with steel, the resulting material composites fail due to an increased hot cracking tendency and micro-crack formation during cooling [12]. Thus, as shown in Figure 3 (AISI1060-5Zn), a weld structure with increased microcracks forms in the aluminium material with increased micropitting in the contact zone in addition to an air gap (middle) in the combinations investigated (right). A comparable joining behaviour can be observed with the material combinations AISI 1060-5Si and AISI 1060-10Si. For the compound forged AISI 1060-5Si and AISI 1060-10Si samples, a thin joining line was only observed in section 1-1. The addition of this element reduces the diffusion tendency considerably, so that the corresponding element inhibits the formation of a metallurgical bond [6].
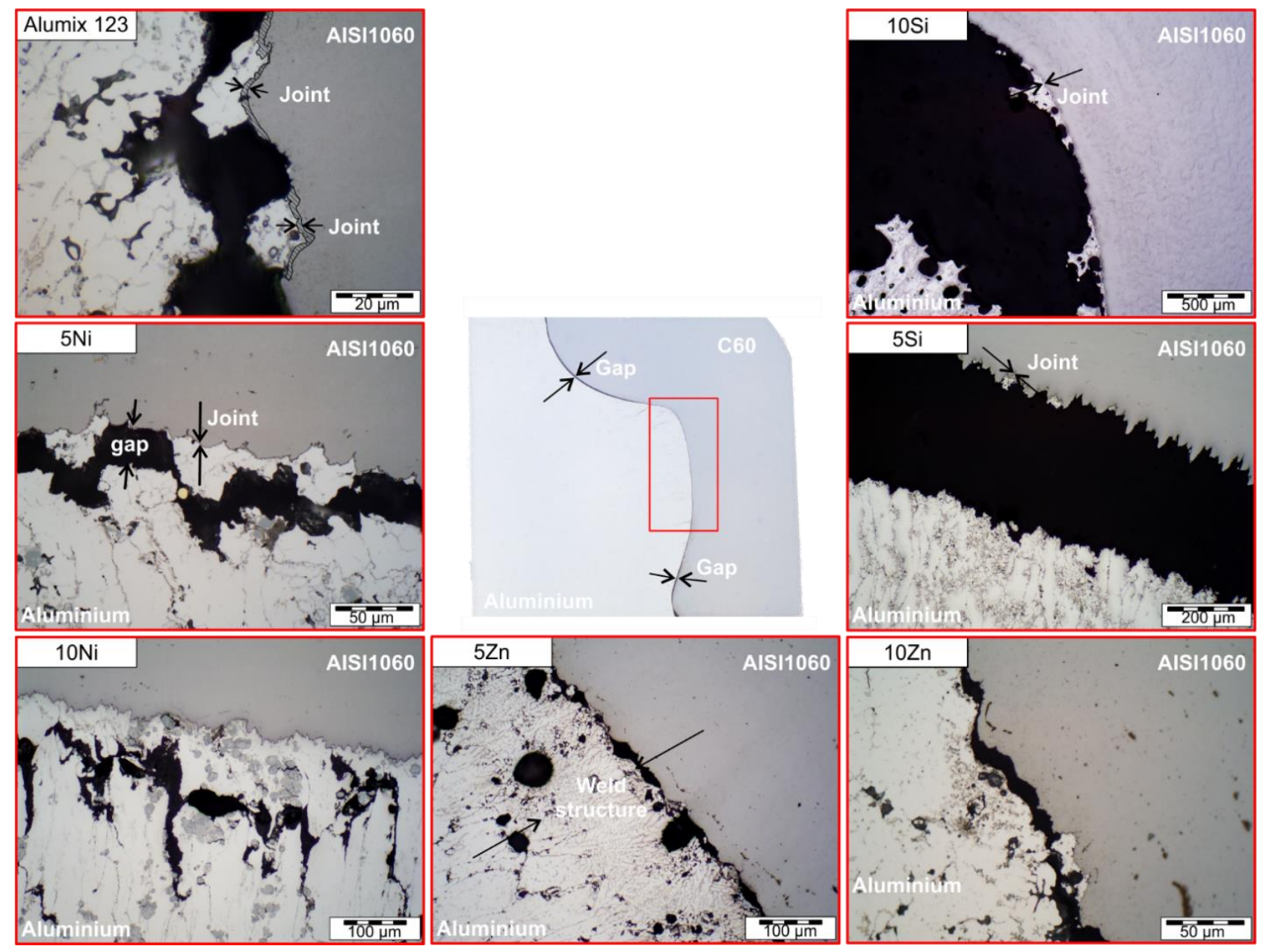

Figure 3 Joining zone of compound forged components in section 1-1 


\section{CONCLUSION}

Within the scope of the present investigations, aluminium cores were individually alloyed with 5 and 10 wt.\% of nickel, silicon and zinc and manufactured by powder metallurgy. Subsequently, the workpieces were combined with AISI 1060, heated to forming temperature and were afterwards compound forged. After quenching, the geared hybrid components were cut and the influence of surface expansion and the respective alloying elements on joint formation was investigated by light microscopy. It was found that a metallurgical joint already occurs starting from a surface expansion of $55 \%$ at the corresponding forming temperatures. In contrast, it could be demonstrated that joint formation highly depends on silicon and nickel. By adding silicon, the thickness of the joining line could be reduced $(5 \mathrm{Si}, 10 \mathrm{Si})$. At the same time, alloying led to a reduction of solidus and liquidus temperatures. As a result of this circumstance, deep shrinkage cavities were detected in all combinations. In summary, alloying influences the joining behaviour to a high degree and results into major challenges in compound forging of steel-aluminium components.

\section{ACKNOWLEDGEMENTS}

\section{The results were obtained in the research project „Compound forging of hybrid powder-solid-parts made of steel and aluminum" financed under project number 310650453 by Deutsche Forschungsgemeinschaft (DFG).}

\section{REFERENCES}

[1] POLITIS, D.J., JIANGUO, L., DEAN, T. Investigation of material flow in forging bi-metal components. Steel Research International. 2012, vol. 14, pp. 231-234.

[2] SPRINGER, H., KOSTKA, A. On the formation and growth of intermetallic phases during interdiffusion between lowcarbon steel and aluminium alloys. Acta Materialia. 2011, No. 59, pp. 1586-1600.

[3] SONG, J.L., LIN, S.B., YANG, C.L., MA, G.C., LIU, H. Spreading behavior and microstructure characteristics of dissimilar metals TIG welding-brazing of aluminium alloy to stainless steel. Materials Science and Engineering. 2009, vol. 509, pp. 31-40.

[4] LEMMENS, B., SPRINGER, H., DUARTE, M.J., DE GRAEVE, I., DE STRRYCKER, J., RAABE, D., VERBEKEN, K. Atom probe tomography of intermetallic phases and interfaces formed in dissimilar joining between Al alloys and steel. Materials Characterization. 2016, vol. 120, pp. 268-272.

[5] YANG, J., YU, Z., LI, Y. ZHANG, H., GUO, W., ZHOU, N. Influence of alloy elements on microstructure and mechanical properties of Al/steel dissimilar joint by laser welding/brazing. Welding in the World. 2018, vol. 62, pp. 427-433.

[6] CHEN, S., HUANG, J., MA, K., ZHANG, H., ZHAO, X. Influence of a Ni-foil interlayer on Fe/Al dissimilar joint by laser penetration welding. Materials Letters. 2012. vol. 79, pp. 296-299.

[7] GROCHE, P., WOHLETZ, S., BRENNEIS, M., PABST, C., RESCH, F. Joining by forming - A review on joint mechanisms, applications and future trends. Journal of Materials Processing Technology. 2014, vol. 214, pp. 19721994.

[8] SPRINGERMATERIALS. Ternary Al-Cu, Al-Cu-Zn, Al-Cu-Si, Al-Cu-Ni phase diagram [online]. [viewed 2020-21-05]. Available from: https://materials.springer.com/.

[9] BEHRENS, B.-A., SOKOLINSKAJA, V., CHUGREEVA, A., DIEFENBACH, J., THÜRER, S., BOHR, D. Investigation into the bond strength of the joining zone of compound forged hybrid aluminium-steel bearing bushing. In AIP Conference Proceedings: Proceedings of the 22nd International ESAFORM Conference on Material Forming. Vitoria-Gasteiz: AIP Publishing, 2019, vol. 2113, pp. 1-6.

[10] BEHRENS, B.-A., GOLDSTEIN, R., CHUGREEVA, A. Thermomechanical processing for creating bi-metal bearing bushings. In Thermal Processing in Motion 2018: Conference Proceedings of the Thermal Processing in Motion. Spartanburg: ASM International, 2018, pp. 15-21.

[11] MORI, K.-I., BAY, N., FRATINI, L., MICARI, F., TEKKAYA, A. E. Joining by plastic deformation. CIRP Annals Manufacturing Technology. 2013, vol. 62, pp. 673-694.

[12] SIVARAJ, P., KANAGARAJAN, D., BALASUBRAMANIAN, V. Effect of post weld heat treatment on tensile properties and microstructure characteristics of friction stir welded armour grade AA7075-T651 aluminium alloy. Defence Technology. 2014, vol. 10, pp. 1-8. 